\title{
Effectiveness of Hand Care Therapy and Garden Walks That Are Conscious of the Stimulation of the Five Senses for Recovery of Cognitive and Mental and Physical Dysfunction Caused by COVID-19
}

\author{
Seigo Koura1 ${ }^{*}$, Akiko Ikeda1,2, Risa Semba1, Megumi Ito1, Kazuho Nagao3, Kentaro Higashi, \\ Yusuke Kumura4, Hiroki Yokota4 ${ }^{4}$, Shinya Matsutani1, Yasuhiko Fujioka ${ }^{5}$
}

${ }^{1}$ Faculty of Rehabilitation, Nishikyusyu University, Kanzaki, Japan

${ }^{2}$ Sophia Phyto-Therapy College, Tokyo, Japan

${ }^{3}$ Social Welfare Corporation Kanjikai, Miyakonojyo, Japan

${ }^{4}$ Department of Rehabilitation Center, St. Mary's Hospital, Kurume, Japan

${ }^{5}$ Fujioka Hospital, Saga, Japan

Email: ^symkoura3@gmail.com

How to cite this paper: Koura, S., Ikeda, A., Semba, R., Ito, M., Nagao, K., Higashi, K., Kumura, Y., Yokota, H., Matsutani, S. and Fujioka, Y. (2021) Effectiveness of Hand Care Therapy and Garden Walks That Are Conscious of the Stimulation of the Five Senses for Recovery of Cognitive and Mental and Physical Dysfunction Caused by COVID-19. Open Journal of Therapy and Rehabilitation, 9, 10-27. https://doi.org/10.4236/ojtr.2021.91002

Received: January 9, 2021

Accepted: February 23, 2021

Published: February 26, 2021

Copyright $\odot 2021$ by author(s) and Scientific Research Publishing Inc. This work is licensed under the Creative Commons Attribution International License (CC BY 4.0).

http://creativecommons.org/licenses/by/4.0/ (c) (i) Open Access

\begin{abstract}
The Japan Dementia Prevention Society conducted a questionnaire survey of dementia specialists conducted in August 2020. Regarding the worsening of symptoms in people with dementia, $8 \%$ answered that they "accept more" and $32 \%$ answered that they "recognize a minority". In the previous research report (Open Journal of Therapy and Rehabilitation Vol.8 No.3), we examined whether hand care therapy (HCT) as one of the passive horticultural therapy was effective in preventing dementia/MCI. Start of the test in August 2018 (I: BL) to February 2020 (VII: 18M) was, the use of HCT was to be effective in preventing dementia and MCI illness and slowing progression. Due to the COVID19 pandemic, VIII (24M) was evaluated in August 2020, and IX (27M) also measured ANS during activity. At that time, they divided into the Group E who had refrained from welfare facilities for the elderly due to the influence of COVID19 and the Group F who HCT continued. In the evaluation of VIII (24M), it was found that the cognitive function of the Group E was significantly reduced compared to VII, and Group F did not show a significant decrease. ADL decreased and depressive symptoms increase by continuing a life with less going out due to the influence of COVID 19 regardless of the use of the facility. It became clear that both Group E and Group F show good changes in ANS balance in the IX. Therefore, by utilizing horticultural
\end{abstract}


therapy that the power of nature and plants in addition to utilizing welfare facilities for the elderly, cognitive impairment in COVID 19. It was expected to lead to prevention and prevention of negative psychology and behavior such as depressive views and depressive tendencies. In the previous research report (Open Journal of Therapy and Rehabilitation Vol.8 No.3), we examined whether hand care therapy (HCT) as one of passive horticultural therapy was effective in preventing dementia/MCI. In the trend from the start of the test in August 2018 (I: BL) to February 2020 (VII: 18M) was, the use of HCT was shown to be effective in preventing dementia and MCI illness and slowing progression. Due to the COVID19 pandemic, various activity restrictions have been implemented in Japan since March 2020, and the number of elderly people who do not receive long-term care or rehabilitation has increased. Therefore, in August and November 2020, when the spread of COVID19 was reduced, cognitive function evaluation was carried out. At that time, they divided into the elderly group (Group E) who had refrained from welfare facilities for the elderly due to the influence of COVID19 and the elderly group (Group F) who HCT continued.

\section{Keywords}

Dementia, MCI, ANS, Hand Care, Prevention, COVID-19

\section{Introduction}

In general, dementia needs to be addressed by various researchers to reduce the risk of morbidity and progression. And dementia was regarded as one of the lifestyle-related diseases, and it is estimated that about $10 \%$ of MCI (Mild cognitive impairment) progresses to dementia in one year.

Active and passive horticultural therapy technique has the characteristic that true communication can be easily constructed because it can improve the euphoria of the treated side [1] [2]. Many elderly people refrained from going out because the announcement of a state of emergency due to the COVID-19 epidemic called for refraining from going out. As a result, not only the amount of activity has decreased, but also the interaction with neighbors, relatives and acquaintances, and the use of welfare facilities for the elderly have decreased, and it is possible that social isolation has progressed [3]. This tendency was particularly strong in the elderly living alone, and it had been reported that the risk of depression increases due to refraining from going out [4] [5] [6].

A study of 20 European countries found that the number of people infected with COVID-19, and the number of deaths were negatively correlated with the average vitamin D levels in those countries [7] [8]. According to a report from the Philippines, COVID-19 became more severe in cases with a vitamin D concentration of less than $30 \mathrm{ng} / \mathrm{mL}$, whereas it was mostly mild in cases with a vitamin D concentration of $30 \mathrm{ng} / \mathrm{mL}$ or more. It was presumed that the risk of dementia progression increases as the new lifestyle of isolation continues [9]. 
Then, psychogeriatric medical care often takes time. Therefore, not only the care of the psychological conditions of the elderly person, but also the care of the medical person or family caregiver side is important. Multi-sensory stimulation is beneficial to a wide variety of conditions typical of geriatric patients and changes appeared in muscle tension, skin conductance and pulse that correlate with reduced blood pressure [10]. In other words, engaging in horticultural activities may help improve the stability of the mind and generally facilitate a much broader and more positive attitude.

It has been suggested that loneliness, especially emotional loneliness, is an important risk factor for the development of dementia in the general elderly in Japan [11]. And the dynamics of the senses play an important role beyond mere reason and sensibility in people's lives [12]. The hand care therapy (HCT) included in the horticultural therapy which is the alternative medicine that utilized a plant, or its essential oil is utilized in various application scenes.

In recent studies, HCT which was not active horticultural therapy but uses plant components as a passive horticultural therapy or aromatherapy technique, was expecting applicable to patients with early and severe dementia that cannot apply active horticultural therapy [13] [14].

On the other hand, dementia was regarded as one of the lifestyle-related diseases, and it is estimated that about $10 \%$ of MCI (Mild cognitive impairment) progresses to dementia in one-year [15].

From the perspective of preventing the conversion from MCI to dementia, the effectiveness of HCT was applied to cognitive impairment, iADL, and senile depression during the period from I (BL: August 2019) to VII (18M: February 2020). In the results, the use of HCT was shown to be effective in preventing dementia and MCI illness and slowing progression [16].

However, in Japan, the number of elderly people who do not provide long-term care or outpatient rehabilitation has increased since March 2020, when the COVID 19 pandemics occurred. Nine members of Group A $(n=24)$ in this study suspended the use of welfare facilities for the elderly for more than 3 months. Seven of them resumed use of welfare facilities for the elderly from June to July 2020 , and two stopped using the facilities.

A cognitive function assessment was performed in VIII (24M: Aug.2020) and IX (27M: Nov.2020) when the prevalence of COVID 19 decreased. At that time, it was divided into Group E $(\mathrm{N}=7)$ who interrupted the use of welfare facilities for the elderly due to the influence of COVID 19 and group F ( $n=15)$ who continued to use the facilities and HCT.

Therefore, cognitive function assessment was performed in VIII (24M: Aug.2020) and IX (27M: Nov.2020) when the prevalence of COVID 19 decreased.

\section{Subjects and Methods}

\subsection{Subjects}

\section{Elderly Subjects}


Continuing from the previous study, the elderly in this study lived in A city, with a population of about $160,000,31.8 \%$ of those 65 years old or over and $16.1 \%$ of those 75 years old or over, which was the average region in Japan. The elderly people studied are those of Group A $(n=24)$ in the previous study. Group E consisted of 4 women and 3 men, was a community-dwelling elderly person in an age of $82.0 \pm 10.8$ years, and the average degree of care required as of August 2020 (VIII) were of $2.2 \pm 0.7$. Group F consisted of 11 women and 4 men and were an elderly person in an age of $84.7 \pm 7.1$ years, and a degree of care required of $2.1 \pm 0.5$.

The elderly people studied are those of Group A $(n=24)$. However, in Japan, the number of elderly people who do not provide long-term care or outpatient rehabilitation has increased since March 2020, when the COVID 19 pandemics occurred. The target elderly welfare facilities were not closed, but weekly HCT activities were suspended from March to July 2020 and resumed in August 2020.

Nine members of Group A in this study suspended the use of welfare facilities for the elderly for more than 3 months. Seven of them resumed use of welfare facilities for the elderly from June to July 2020 , and two stopped using the facilities. Therefore, these 7 people were designated as Group E, and the other 15 elderly people of Group A who continued to use the facility were designated as Group F. Group E consisted of 4 women 3 men, was an age of $82.0 \pm 10.8$ years, and the average degree of care required as of August 2020 (VIII) were of $2.2 \pm$ 0.7 . Group F consisted of 11 women 4 men and was an elderly person in an age of $84.7 \pm 7.1$ years, and a degree of care required of $2.1 \pm 0.5$.

\subsection{Methods}

\subsubsection{HCT Study Design 1}

All hand care treatments were handled by hand care therapists certified by the Japan Society of Phyto-therapy. Hand care therapists also included occupational therapy students. Furthermore, all evaluations were performed by occupational therapists. HCT is a touch care that sits in front of the subject, values relaxed breathing, and gently touches while building a relationship of trust with the other party.

The study design is shown in Figure 1. We recruited 320 participants community-dwelling adults aged 70 years or older with memory problems. All were participants in community health classes and informed consent of evaluation was obtained from all participants prior to their inclusion in the study. The informed consent also confirmed the provision of feedback on the protocol and the data obtained, and all study participants solicited for feedback.

The group A had 24 elderly patients who underwent HCT on a weekly basis in addition to their regular care programs $(84.1 \pm 4.3$ years). The placebos A consisted of 22 elderly persons who responded only to regular care programs (81.9 \pm 3.4 years).

The group B had 22 elderly patients who underwent HCT on a weekly basis in addition to their regular local health classes $(83.3 \pm 5.1$ years). The placebos $B$ 


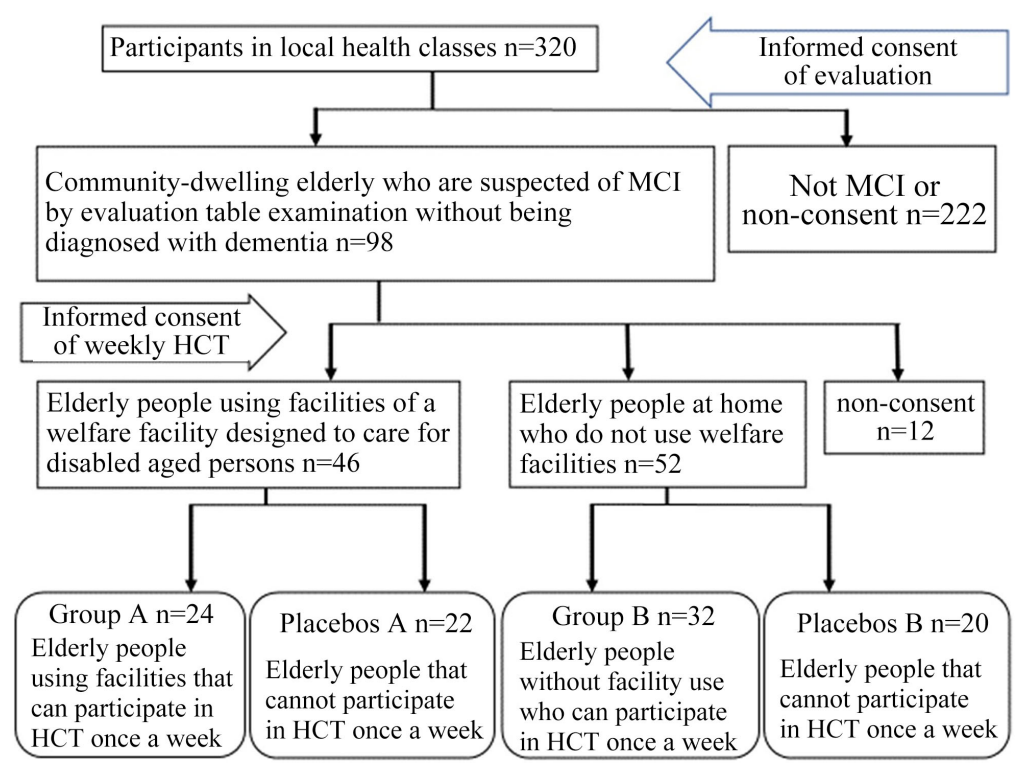

Figure 1. Flow chart for selection of HCT group and placebo group.

consisted of 32 elderly persons who responded only to regular local health classes (82.7 \pm 3.8 years).

Occupational therapists or caregivers performed a cognitive assessment of MMSE and Moca-J on the 320 recruited patients, and 72 were "MCI suspected". Seventy-two elderly persons suspected of having MCI were divided into 34 persons who used a daycare-type elderly welfare facility and 32 persons who did not.

Of the 34 persons using the outpatient-type elderly welfare facilities, 24 patients who wished to undergo HCT once a week were classified as Group A, and 10 persons that did not wish to receive HCT were classified as a placebo group. Among the 32 persons that did not use the outpatient-type elderly welfare facilities, 22 persons that wished to undergo HCT once a week were group B, and 10 persons that who did not wish to do so were added to the placebo group.

The cognitive evaluation, $\mathrm{AADL}$, and depression evaluation performed at this time were baseline values, and evaluation was continued every three months thereafter (I-IIV).

\subsubsection{HCT Study Design 2}

Figure 2 shows a study design to confirm the presence or absence of the effects of COVID19.

From August 2018 (Base Line) to February 2020 (18M), we could evaluate cognitive ability every three months, but in May 2020 (21M), it could not be evaluated due to the influence of COVID19.

Afterwards, cognitive function evaluation was performed at the timing of VIII (24M: Aug.2020) and IX (27M: Nov.2020) when the prevalence of COVID19 decreased. At that time, they were divided into group $\mathrm{E}(\mathrm{n}=7)$ and group $\mathrm{F}(\mathrm{n}=$ 15). VIII and IX evaluated cognitive impairment, iADL and depressive tendency 


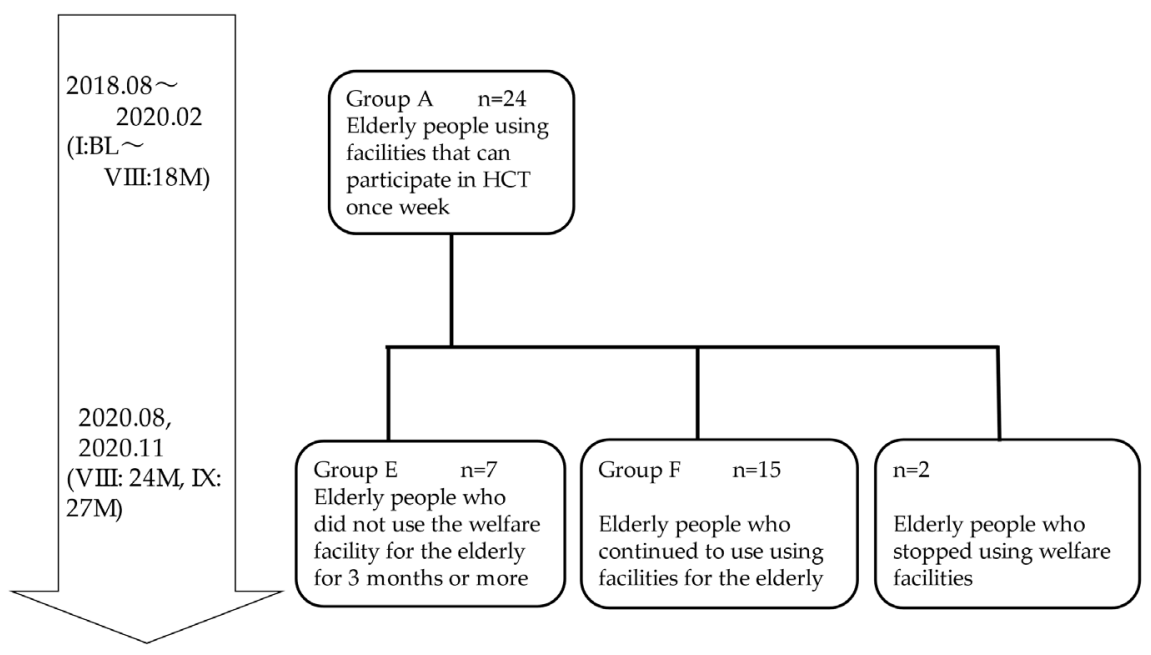

Figure 2. Group A Flow chart for grouping 24 people into groups E and F.

using evaluation sheets. In addition, IX investigated changes in autonomic balance using objective indicators such as spectral electrocardiogram (ECG) analysis (heart rate variability: HRV analysis) before and after active/passive horticultural therapy.

\subsubsection{HCT Design}

The times required for every event were preparation; 2 - 3 min, Base Line Resting; $3 \mathrm{~min}$, Interval 1; $1 \mathrm{~min}$, Right hand HCT; 5 - $7 \mathrm{~min}$, Interval 2; 1 - $2 \mathrm{~min}$, Left hand HAT: 5 - 7 min, Rest after HAT; 3 - 5 min.

\subsection{Horticultural Therapy Garden Walk and HCT ANS Measurement Design}

In the IX (27M) term, changes in the active ANS balance of group E and group F were measured during and during walking, including wheelchair walking in the horticultural therapy garden. The ANS measurement of HCT as a passive horticultural therapy was performed before and after the procedure and during the procedure.

The time of every event in HTG walk was Base Line Resting; 5 min., Transfer for outdoor horticultural therapeutic garden (HTG); 5 - 7 min., Time of the olfactory stimulation by favorite herb plants (apple mint, lemon balm, rosemary, lavender); 3 - $5 \mathrm{~min}$., Sweetness stimulation by stevia leaf; 2 - $3 \mathrm{~min}$., Tactile stimulation by lambsear; $2-3 \mathrm{~min}$. Finally, transfer for resting room; $5-7 \mathrm{~min}$. The total time for these activities was 25 - 30 minutes.

A spectral electrocardiogram (ECG) analysis (heart rate variance: HRV analysis) was performed using software, Mem Calc/Tarawa system (GMS, Japan), which is a non-invasive, real-time analysis system. ECG was measured using a continuous-wave frequency spectrum analysis, the sympathetic nervous system (SNS: Low Frequency (LF)/High Frequency (HF)) has been retracted, the parasympathetic nervous system (PNS: HF) was confirmed to be enhanced (Figure 3) [17] [18]. 


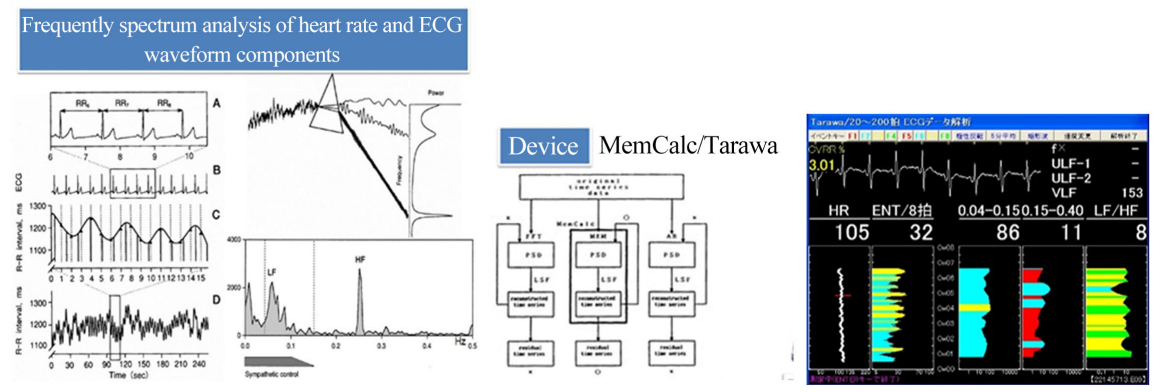

Figure 3. A temporal change of the Parasympathetic Nervous System (PNS) in a relaxed state and the Sympathetic Nervous System (SNS) in a strain state was measured using ECG and the analysis software (GMS co. Ltd. Mem Calc/Tarawa) [19] [20]. * HF value = PNS, LF/HF value = SNS. LF: $0.04-0.15 \mathrm{~Hz}$ reflects parasympathetic function and some sympathetic function. HF: $0.15-0.4 \mathrm{~Hz}$ is related to respiratory and heart rate variability, PNS function almost and that is reflected in the indicators used in the SNS ratio LF/HF.

\subsection{Equipment and Scales}

\subsubsection{Changes in Cognition, Life, and Depression Evaluation over Time with HCT}

The elderly persons with Mini-Mental State Examination (as follows, MMSE) screening tool score of 24 - 27 or Montreal Cognitive Assessment Japanese version (Moca-J) screening tool score 25 or less in the pre-evaluation was designated [19]-[26]. The timing of the evaluation was HCT initiation (Base Line), 3 months later, 6 months later, 9 months later, 12 months later, 15 months later and 18 months later. The transition from MCI to dementia was judged by MMSE evaluation.

In addition to MMSE and Moca-J evaluations, iADL evaluations and evaluations of depression tendency were also conducted, and the transition of the evaluation points was also confirmed. Changes over time in the various evaluations after nine months were compared with those at the start. MMSE and Moca-J score showed cognitive evaluation. Tokyo Metropolitan Institute of Gerontology (TMIG-index) of Competence [27] [28], which was iADL evaluation and Geriatric depression scale 15 (GDS15) [29] [30] were used.

\subsubsection{MMSE Screening Tool}

MMSE was the most commonly used instrument for the assessment of cognitive function in both clinical and research settings. It was usually used as a screening test for dementia and cognitive impairment or as a brief cognitive assessment that takes about $10 \mathrm{~min}$ to complete. In Table 1, Instructions for administration and scoring of the MMSE were orientation (10 points), registration (3 points), at tension and calculation ( 5 points), recall ( 3 points), language and praxis ( 9 points).

\subsubsection{Moca-J Screening Tool}

The Moca-J evaluation was the Japanese version of Moca-J evaluation. The Moca-J Test was validated in the setting of mild cognitive impairment (MCI), and has been subsequently adopted in numerous clinical settings. The sensitivity of 
the Moca-J for detecting $\mathrm{MCI}$ is $90 \%$, compared to $18 \%$ for other leading cognitive screening tools such as the MMSE. The Moca-J assesses were short term memory, visuospatial abilities, executive functions, attention, concentration and working memory, language, orientation to time and place. Read list of words, subject must repeat them. Do 2 trials. Do a recall after 5 minutes.

\subsubsection{TMIG-Index of Competence}

Elderly populations are evaluated on their ability to perform instrumental activities of daily living (IADL) using one of three sub-scales in the TMIG Index of Competence, while the Basic Checklist-a tool developed to screen for frailty-is designed to measure actual task performance.

\subsubsection{GDS15}

Diagnosing depression in the elderly poses a serious problem because of the ageing process and various diseases that influence and mask symptoms of depressed mood. For instance, depression is often confused with dementia. It is therefore crucial to use a diagnostic tool that takes these problems into account. Symptoms of depression were assessed using the 15-item Geriatric Depression Scale (GDS-15) and demonstrated validity among ambulatory elderly.

\subsection{Surgical Therapists and Students}

3 occupational therapist and twenty healthy student volunteers (There was not a continuous disease; a having more than $90 \%$ of attendances of the required subject of the university student; 8 male and 12 females; mean age $20.4 \pm 0.7$ years) were enrolled. 3 occupational therapists, more than 10 years after obtaining the qualification, were in charge, and three women and two men were $35.2 \pm 3.7$ years old.

Regarding the suitability of sample size, the significance level was set to 0.05 , and the method was a two-sided test, and the power for comparing the mean values of the two groups was calculated. As a result, the total power of $\mathrm{n}=320$ were 0.99 . The power of each test plot was 0.64 for the $n=32$ plots and 0.41 for the $\mathrm{n}=20$ plots, which was less than 0.8 .

Table 1. MMSE changes over time every three months.

\begin{tabular}{|c|c|c|c|c|c|c|c|c|c|c|c|}
\hline & $\begin{array}{c}\text { I. BL } \\
\text { Aug. } 2019\end{array}$ & $\begin{array}{c}\text { II. } 3 \mathrm{M} \\
\text { Nov. } 2018\end{array}$ & $\begin{array}{c}\text { III. } 6 \mathrm{M} \\
\text { Feb. } 2019\end{array}$ & $\begin{array}{c}\text { IV. } 9 \text { M } \\
\text { May } 2019\end{array}$ & $\begin{array}{l}\text { V. } 12 \mathrm{M} \\
\text { Aug. } 2019\end{array}$ & $\begin{array}{c}\text { VI. } 15 \mathrm{M} \\
\text { Nov. } 2019\end{array}$ & $\begin{array}{l}\text { VII. } 18 \mathrm{M} \\
\text { Feb. } 2020\end{array}$ & $\begin{array}{c}\text { Not } \\
\text { evaluated }\end{array}$ & $\begin{array}{l}\text { VIII. } 24 \mathrm{M} \\
\text { Aug. } 2020\end{array}$ & $\begin{array}{c}\text { IX. } 27 \mathrm{M} \\
\text { Nov. } 2020\end{array}$ & ANOVA \\
\hline $\begin{array}{c}\text { Group E } \\
n=7\end{array}$ & $26.1 \pm 3.1$ & $26.3 \pm 3.5$ & $27.1 \pm 2.2$ & $26.3 \pm 2.6$ & $26.2 \pm 2.6$ & $26.9 \pm 2.5$ & $26.7 \pm 2.1$ & & $21.1 \pm 2.6$ & $23.1 \pm 1.9$ & $\begin{array}{c}\mathrm{I}>\mathrm{VIII}^{*} \\
\mathrm{II}>\mathrm{VIII}^{*} \\
\mathrm{III}>\mathrm{VIII}^{*} \\
\mathrm{IV}>\mathrm{VIII}^{*} \\
\mathrm{~V}>\mathrm{VIII}^{*} \\
\mathrm{VI}>\mathrm{VIII}^{*} \\
\mathrm{VII}>\mathrm{VIII}^{* *}\end{array}$ \\
\hline $\begin{array}{c}\text { Group F } \\
n=15\end{array}$ & $25.4 \pm 1.8$ & $26.4 \pm 2.2$ & $26.2 \pm 2.2$ & $26.2 \pm 2.1$ & $26.8 \pm 2.4$ & $26.9 \pm 0.8$ & $27.9 \pm 1.1$ & & $27.1 \pm 1.5$ & $27.8 \pm 1.1$ & $\begin{array}{l}\mathrm{I}<\mathrm{VII}^{*} \\
\mathrm{I}<\mathrm{IX}^{* *}\end{array}$ \\
\hline
\end{tabular}

Mean value \pm standard deviation ${ }^{*} \mathrm{p}<0.05,{ }^{* *} \mathrm{p}<0.01$. One-way analysis of variance, multiple comparison Tukey. March 2020 could not be evaluated due to the influence of COVID19. 


\subsection{Statistical Analysis}

The results of ANS were shown as mean \pm SD (min-max), Interquartile range, Median, statistical significance was checked. The One-way analysis of variance, multiple comparisons Tukey tests were performed in Evaluation of various questionnaires.

\subsection{Ethical Considerations}

We strictly observed the Helsinki Declaration of 2015 (revised in 2013), explained the purpose and outline of this study to them and obtained informed consent from them beforehand. All procedures were approved by the $\mathrm{Ni}$ shi-Kyushu University (Saga, Japan) Ethics Committee (H29-5, 2017).

\section{Results}

\subsection{HCT}

Subjects were selected from the elderly who had not been diagnosed with dementia or MCI. According to MMSE and Moca-J (MCI screening tools), there was more than one in four elderly people were classified as MCI or dementia.

As mentioned earlier, in general, the transition from MCI to dementia is about $10 \%$ per year. When comparing the evaluation of MMSE and Moca-J 18 months later (VII) with BL, the average values of Group A and Group B showed a significant upward trend, placebo A was the status quo, and placebo B was it showed a tendency to decrease significantly (Table 1 , Table 2).

Due to the influence of COVID19, it was impossible to evaluate 21M in May 2020. In addition, 9 out of 24 members of Group A had subjects who suspended the use of welfare facilities for the elderly for 3 months or more from March 2020, and both active horticultural therapy and HCT were suspended for 3 months. A cognitive function assessment was performed in VIII (24M: Aug.2020) and IX (27M: Nov.2020) when the prevalence of COVID 19 decreased. At that time, it was divided into Group E ( $n=7)$ who interrupted the use of welfare facilities for the elderly due to the influence of COVID 19 and group $\mathrm{F}(\mathrm{n}=15)$ who continued to use the facilities and HCT.

An assessment of VIII, which also resumed use of welfare facilities for the elderly, found that Group E had significantly reduced cognitive function compared to all I to VII (Table 1, Table 2). On the other hand, Group F, who continued to receive care techniques such as HCT at the facility, did not show a significant decrease in cognitive function in the comparison of VII and VIII. The activity index TMIG-Index was clearly lower in both groups, and Group F was significantly lower than V and VI (Table 3). The depression index GDS clearly increased in both Group E and Group F, and Group F was significantly higher than VII (Table 4). The presence or absences of a significant difference between TMIG-Index and GDS were influenced by the $\mathrm{N}$ number. In the evaluation of IX, only GDS took significantly higher than VII compared with VIII, but TMIG-Index and GDS showed a tendency to improve more than VIII. In Group 
Table 2. Moca-J changes over time every three months.

\begin{tabular}{|c|c|c|c|c|c|c|c|c|c|c|c|}
\hline & $\begin{array}{c}\text { I. BL } \\
\text { Aug. } 2019\end{array}$ & $\begin{array}{c}\text { II. } 3 \mathrm{M} \\
\text { Nov. } 2018\end{array}$ & $\begin{array}{c}\text { III. } 6 \mathrm{M} \\
\text { Feb. } 2019\end{array}$ & $\begin{array}{c}\text { IV. } 9 \text { M } \\
\text { May } 2019\end{array}$ & $\begin{array}{c}\text { V. } 12 \mathrm{M} \\
\text { Aug. } 2019\end{array}$ & $\begin{array}{l}\text { VI. } 15 \mathrm{M} \\
\text { Nov. } 2019\end{array}$ & $\begin{array}{l}\text { VII. } 18 \mathrm{M} \\
\text { Feb. } 2020\end{array}$ & $\begin{array}{c}\text { Not } \\
\text { evaluated }\end{array}$ & $\begin{array}{l}\text { VIII. } 24 \mathrm{M} \\
\text { Aug. } 2020\end{array}$ & $\begin{array}{c}\text { IX. } 27 \mathrm{M} \\
\text { Nov. } 2020\end{array}$ & ANOVA \\
\hline $\begin{array}{c}\text { Group E } \\
\mathrm{n}=7\end{array}$ & $22.9 \pm 5.1$ & $21.4 \pm 4.5$ & $23.7 \pm 5.2$ & $22.4 \pm 5.1$ & $22.3 \pm 3.5$ & $22.3 \pm 4.8$ & $25.4 \pm 3.6$ & & $18.3 \pm 2.4$ & $20.4 \pm 5.2$ & ns \\
\hline $\begin{array}{c}\text { Group F } \\
\mathrm{n}=15\end{array}$ & $20.7 \pm 2.4$ & $21.6 \pm 5.6$ & $21.2 \pm 3.7$ & $21.7 \pm 2.8$ & $23.6 \pm 2.9$ & $24.4 \pm 4.3$ & $25.5 \pm 3.2$ & & $24.6 \pm 4.2$ & $24.2 \pm 5.7$ & $\begin{aligned} \mathrm{I} & <\mathrm{VII}^{*} \\
\mathrm{I} & <\mathrm{IX}^{*} \\
\mathrm{II} & <\mathrm{IX}^{*} \\
\mathrm{III} & <\mathrm{VII}^{*} \\
\mathrm{III} & <\mathrm{IX}^{*}\end{aligned}$ \\
\hline
\end{tabular}

Mean value \pm standard deviation ${ }^{*} \mathrm{p}<0.05,{ }^{* *} \mathrm{p}<0.01$. One-way analysis of variance, multiple comparison Tukey. March 2020 could not be evaluated due to the influence of COVID19.

Table 3. TIMG-index changes over time every three months.

\begin{tabular}{|c|c|c|c|c|c|c|c|c|c|c|c|}
\hline & $\begin{array}{c}\text { I. BL } \\
\text { Aug. } 2019\end{array}$ & $\begin{array}{c}\text { II. } 3 \mathrm{M} \\
\text { Nov. } 2018\end{array}$ & $\begin{array}{c}\text { III. } 6 \mathrm{M} \\
\text { Feb. } 2019\end{array}$ & $\begin{array}{c}\text { IV. } 9 \text { M } \\
\text { May } 2019\end{array}$ & $\begin{array}{c}\text { V. } 12 \mathrm{M} \\
\text { Aug. } 2019\end{array}$ & $\begin{array}{c}\text { VI. } 15 \mathrm{M} \\
\text { Nov. } 2019\end{array}$ & $\begin{array}{l}\text { VII. } 18 \mathrm{M} \\
\text { Feb. } 2020\end{array}$ & $\begin{array}{c}\text { Not } \\
\text { evaluated }\end{array}$ & $\begin{array}{l}\text { VIII. } 24 \mathrm{M} \\
\text { Aug. } 2020\end{array}$ & $\begin{array}{c}\text { IX. } 27 \mathrm{M} \\
\text { Nov. } 2020\end{array}$ & ANOVA \\
\hline $\begin{array}{c}\text { Group E } \\
\mathrm{n}=7\end{array}$ & $8.4 \pm 2.8$ & $8.4 \pm 3.5$ & $8.7 \pm 3.2$ & $8.4 \pm 3.1$ & $8.6 \pm 2.6$ & $8.3 \pm 2.5$ & $8.6 \pm 2.9$ & & $6.7 \pm 2.1$ & $7.4 \pm 2.3$ & ns \\
\hline $\begin{array}{c}\text { Group F } \\
\mathrm{n}=15\end{array}$ & $7.7 \pm 1.3$ & $7.3 \pm 1.4$ & $7.5 \pm 1.1$ & $7.4 \pm 2.6$ & $8.6 \pm 1.8$ & $8.6 \pm 2.7$ & $7.7 \pm 2.3$ & & $5.9 \pm 1.7$ & $6.3 \pm 2.1$ & $\begin{array}{l}\mathrm{V}>\mathrm{VIII}^{*} \\
\mathrm{VI}>\mathrm{VIII}^{*}\end{array}$ \\
\hline
\end{tabular}

Mean value \pm standard deviation ${ }^{*} \mathrm{p}<0.05,{ }^{* *} \mathrm{p}<0.01$. One-way analysis of variance, multiple comparison Tukey. March 2020 could not be evaluated due to the influence of COVID19.

Table 4. GDS changes over time every three months.

\begin{tabular}{|c|c|c|c|c|c|c|c|c|c|c|c|}
\hline & $\begin{array}{c}\text { I. BL } \\
\text { Aug. } 2019\end{array}$ & $\begin{array}{c}\text { II. } 3 \mathrm{M} \\
\text { Nov. } 2018\end{array}$ & $\begin{array}{c}\text { III. } 6 \mathrm{M} \\
\text { Feb. } 2019\end{array}$ & $\begin{array}{c}\text { IV. } 9 \text { M } \\
\text { May } 2019\end{array}$ & $\begin{array}{l}\text { V. } 12 \mathrm{M} \\
\text { Aug. } 2019\end{array}$ & $\begin{array}{c}\text { VI. } 15 \mathrm{M} \\
\text { Nov. } 2019\end{array}$ & $\begin{array}{l}\text { VII. } 18 \mathrm{M} \\
\text { Feb. } 2020\end{array}$ & $\begin{array}{c}\text { Not } \\
\text { evaluated }\end{array}$ & $\begin{array}{l}\text { VIII. } 24 \mathrm{M} \\
\text { Aug. } 2020\end{array}$ & $\begin{array}{c}\text { IX. } 27 \mathrm{M} \\
\text { Nov. } 2020\end{array}$ & ANOVA \\
\hline $\begin{array}{c}\text { Group E } \\
\mathrm{n}=7\end{array}$ & $6.2 \pm 3.1$ & $5.1 \pm 2.9$ & $5.7 \pm 4.2$ & $5.9 \pm 5.1$ & $4.3 \pm 3.1$ & $3.6 \pm 2.6$ & $3.1 \pm 1.2$ & & $8.3 \pm 2.1$ & $7.7 \pm 3.7$ & ns \\
\hline $\begin{array}{c}\text { Group F } \\
\mathrm{n}=15\end{array}$ & $6.7 \pm 3.4$ & $6.9 \pm 3.3$ & $7.6 \pm 3.0$ & $5.7 \pm 2.3$ & $6.1 \pm 1.4$ & $5.6 \pm 1.0$ & $4.5 \pm 1.4$ & & $8.1 \pm 1.7$ & $7.2 \pm 1.2$ & $\begin{array}{c}\mathrm{II}>\mathrm{VII}^{*} \\
\mathrm{III}>\mathrm{VII}^{*} \\
\mathrm{IV}<\mathrm{VIII}^{*} \\
\mathrm{VI}<\mathrm{VIII}^{*} \\
\mathrm{VII}<\mathrm{VIII}^{*} \\
\mathrm{VII}<\mathrm{IX}^{*}\end{array}$ \\
\hline
\end{tabular}

Mean value \pm standard deviation ${ }^{*} \mathrm{p}<0.05,{ }^{* *} \mathrm{p}<0.01$. One-way analysis of variance, multiple comparison Tukey. March 2020 could not be evaluated due to the influence of COVID19.

E, although no significant difference was observed, cognitive function, ADL, and depressive symptoms all tended to improve compared to VIII. This is because all elderly people spend a lot of time at home due to the influence of COVID 19, ADL decreases and depressive symptoms increase, and when returning to normal life utilizing elderly welfare facilities, all indicators are I could guess that it would improve.

\subsection{ANS Balance Measurement in a Walk Conscious of the Stimulation of the Five Senses to HTG}

The average HF $(0.15-0.4 \mathrm{~Hz})$ of Group E was $19.1 \pm 16.4\left(\mathrm{msec}^{2} / \mathrm{Hz}\right)$ for "BL", $25.8 \pm 26.1\left(\mathrm{msec}^{2} / \mathrm{Hz}\right)$ for "for HTG", $41.6 \pm 25.0\left(\mathrm{msec}^{2} / \mathrm{Hz}\right)$ for "olfactory", 
$76.9 \pm 47.8\left(\mathrm{msec}^{2} / \mathrm{Hz}\right)$ for "sweetness", $40.6 \pm 24.8\left(\mathrm{msec}^{2} / \mathrm{Hz}\right)$ for "tactile", and $37.3 \pm 17.4\left(\mathrm{msec}^{2} / \mathrm{Hz}\right)$ for "for room". In the significant difference test with "BL", "for HTG" was no significantly $(\mathrm{p}=0.19)$, and the others were significantly lower at the $1 \%$ level (Figure 4).

The average HF/LF index of Group E is $15.7 \pm 11.3$ for "BL", $15.1 \pm 11.8$ for "for HTG", $10.2 \pm 7.3$ for "olfactory", $5.0 \pm 6.4$ for "sweetness", and $4.0 \pm$ for "tactile". 2.8, "for room" was $12.6 \pm 9.1$. In the significance test with "BL", "for HTG" and "for room" were significantly lower at the $5 \%$ level, and the others were significantly lower at the $1 \%$ level (Figure 5).

The average HF $\left(\mathrm{msec}^{2} / \mathrm{Hz}\right)$ of Group F is $20.8 \pm 17.3$ for "BL", $44.4 \pm 53.7$ for "for HTG", $76.3 \pm 42.1$ for "olfactory", $75.5 \pm 56.4$ for "sweetness", and "tactile". It was $46.0 \pm 29.6$ and $39.5 \pm 34.4$ for "for room". In the significance test with "BL", "for HTG" was significantly higher at the 5\% level, and the others were significantly lower at the $1 \%$ level (Figure 6).

The average LF/HF-index of Group F is $17.0 \pm 16.7$ for "BL", $8.6 \pm 4.1$ for "for HTG", $7.0 \pm 5.7$ for "olfactory", $6.8 \pm 8.9$ for "sweetness", and 7.5 for "tactile". It was \pm 7.6 and $7.1 \pm 6.4$ for "for room". In the significance test with "BL", "for HTG" was no significantly $(\mathrm{p}=0.24)$, and the others were significantly lower at the $1 \%$ level (Figure 7).

\section{ANS balance measurement in HCT}

The average HF of Group E during HCT is $8.4 \pm 4.3$ for "BL", $26.4 \pm 17.1$ for "right hand", $9.0 \pm 5.2$ for "Interval", $27.9 \pm 13.2$ for "Left hand" and 14.3 for "rest". It was \pm 6.5 . In the significance test with "BL", "Interval" was not significantly different $(\mathrm{p}=0.14)$, and other than that, it was significantly higher at the $1 \%$ level (Figure 8).

The average HF of Group E during HCT was $8.4 \pm 4.3$ for "BL", $26.4 \pm 17.1$ for "right hand", $9.0 \pm 5.2$ for "Interval", $27.9 \pm 13.2$ for "Left hand" and 14.3 for "rest". It was \pm 6.5 . In the significance test with "BL", "Interval" was not significantly different $(\mathrm{p}=0.11)$, and the others were significantly lower at the $1 \%$ level (Figure 9).

The average HF of Group F during HCT is $7.0 \pm 3.8$ for "BL", $16.9 \pm 4.4$ for "right hand", $9.5 \pm 5.6$ for "Interval", $13.8 \pm 7.1$ for "Left hand" and 10.1 for "rest". It was \pm 4.4. In the significance test with "BL", "Interval" and "rest" were not significantly different $(\mathrm{p}=0.21, \mathrm{p}=0.11)$, and the others were significantly higher at the $1 \%$ level (Figure 10).

The average LF/HF-index of Group F during HCT is $3.6 \pm 0.9$ for "BL", $2.0 \pm$ 1.1 for "right hand", $3.4 \pm 1.1$ for "Interval", $1.6 \pm 0.9$ for "Left hand" and "rest" was $1.9 \pm 0.6$. In the significance test with "BL", "Interval" was not significantly different $(\mathrm{p}=0.13)$, and other than that, it was significantly lower at the $1 \%$ level (Figure 11).

\section{Discussions}

According to the results of the previous research, it was considered that the depressive symptoms were remarkably improved by the weekly HCT operation. 


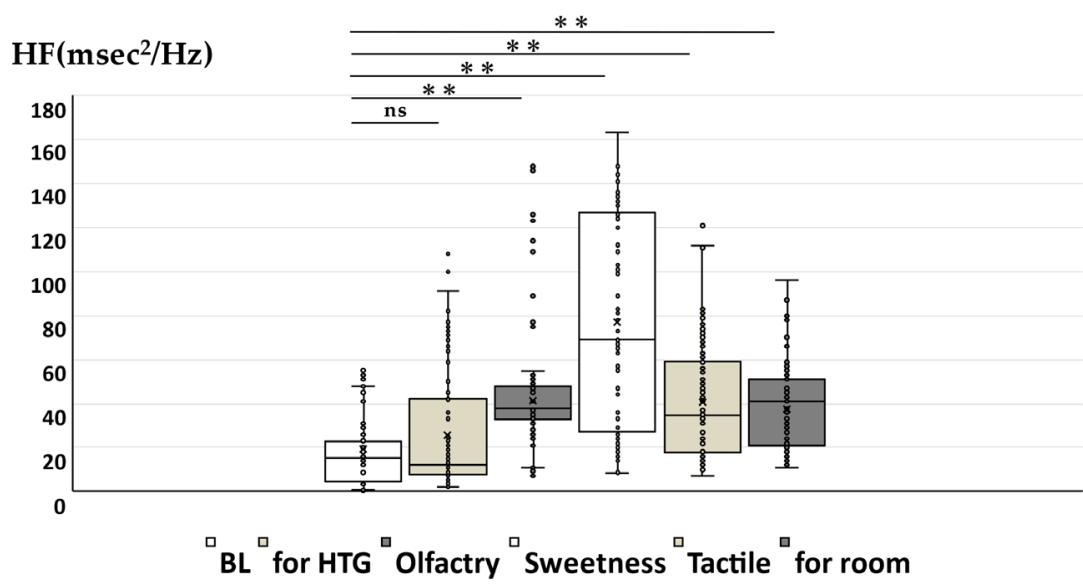

Figure 4. Comparison of ANS balance (HF) in HTG walks based on the stimulation of the five senses of Group E $(n=7)$. The Mann-Whitney $U$ test was performed in in comparison with BL. ns: no significant, ${ }^{\star} \mathrm{p}<0.05,{ }^{\star *} \mathrm{p}<0.01$.

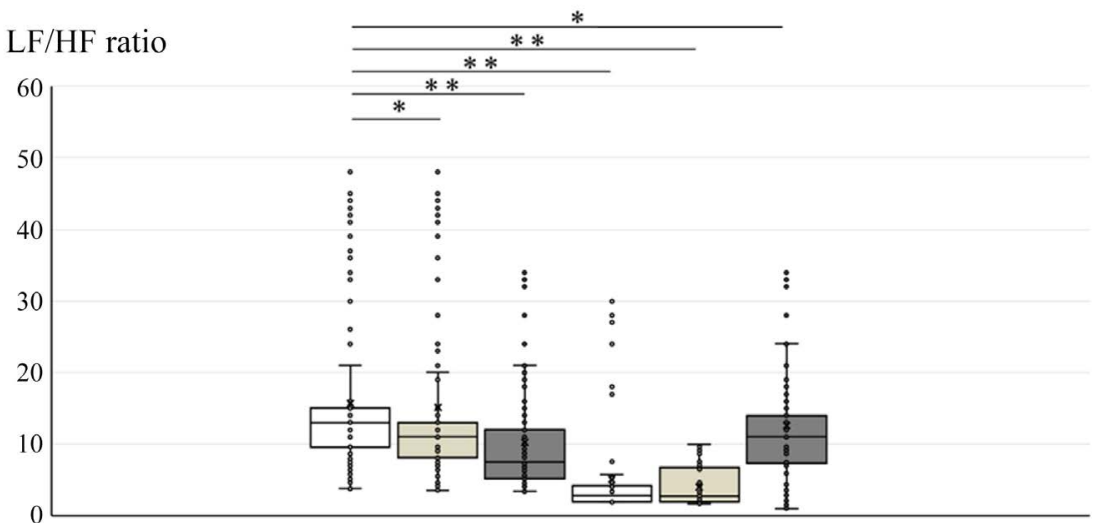

$\square \mathrm{BL}$ afor HTG $\square$ Olfactry $\square$ Sweetness $\square$ Tactile $\square$ for room

Figure 5. Comparison of ANS balance (LF/HF ratio) in HTG walks based on the stimulation of the five senses of Group E $(n=7)$. The Mann-Whitney $U$ test was performed in in comparison with BL. ns: no significant, ${ }^{\star} \mathrm{p}<0.05$, ${ }^{* *} \mathrm{p}<0.01$.

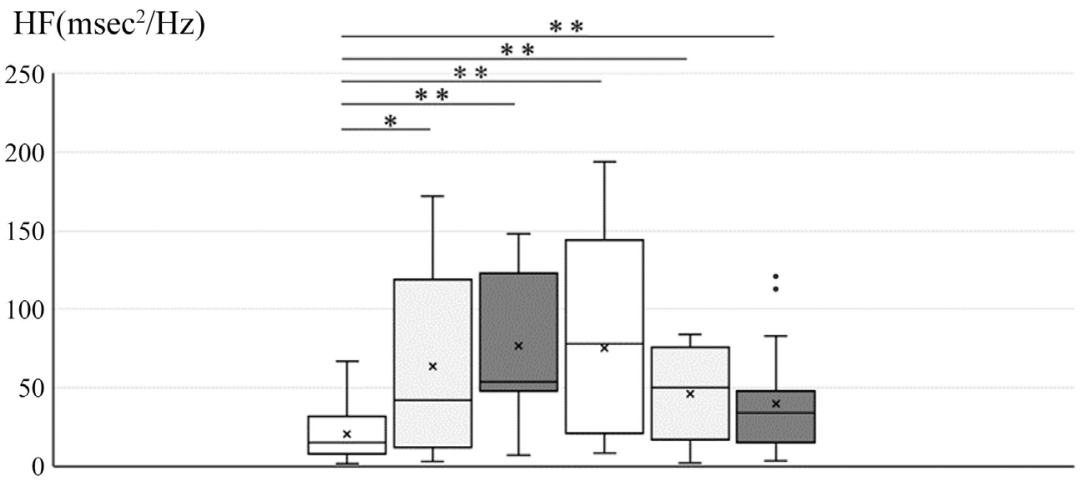

$\square \mathrm{BL}$ - for HTG $\square$ Olfactry $\square$ Sweet $\square$ Tactile $\square$ for room

Figure 6. Comparison of ANS balance (HF) in HTG walks based on the stimulation of the five senses of Group F $(n=15)$. The Mann-Whitney $U$ test was performed in in comparison with BL. ns: no significant, ${ }^{*} \mathrm{p}<0.05,{ }^{* *} \mathrm{p}<0.01$. 


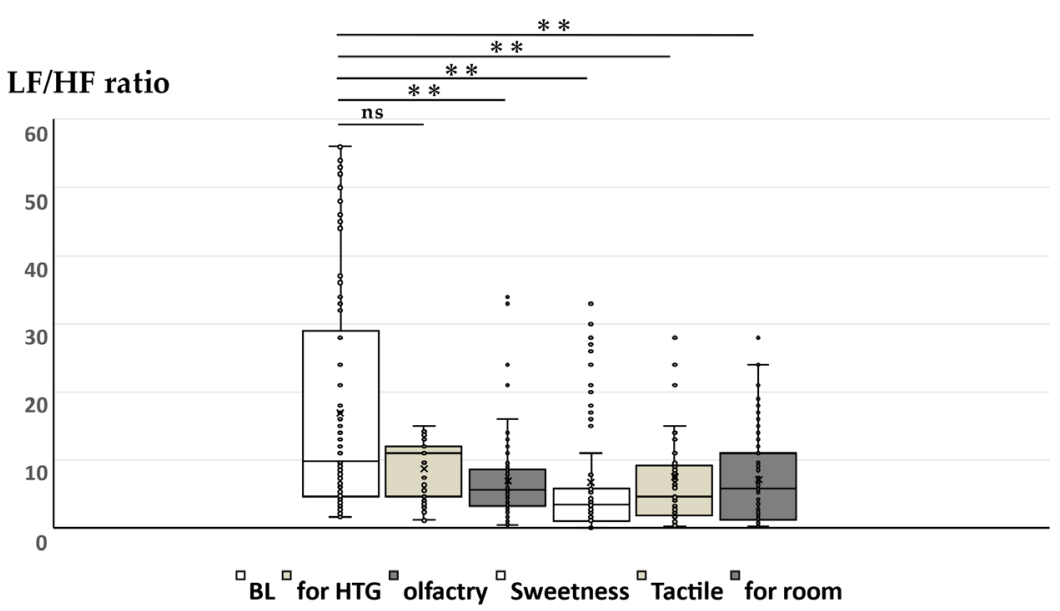

Figure 7. Comparison of ANS balance (LF/HF ratio) in HTG walks based on the stimulation of the five senses of Group F ( $n=15)$. The Mann-Whitney U test was performed in comparison with BL. ns: no significant, ${ }^{\star} \mathrm{p}<0.05,{ }^{\star *} \mathrm{p}<0.01$.

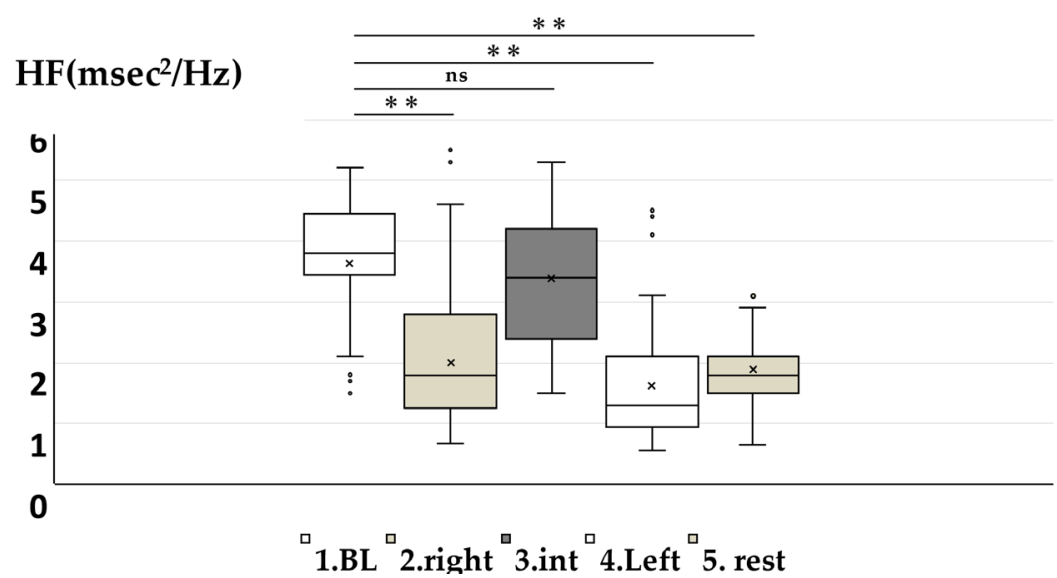

Figure 8. Comparison of ANS balance (HF) in HCT of Group E ( $=7)$. The Mann-Whitney $U$ test was performed in in comparison with BL. ns: no significant, ${ }^{\star} \mathrm{p}<0.05,{ }^{\star *} \mathrm{p}<0.01$.

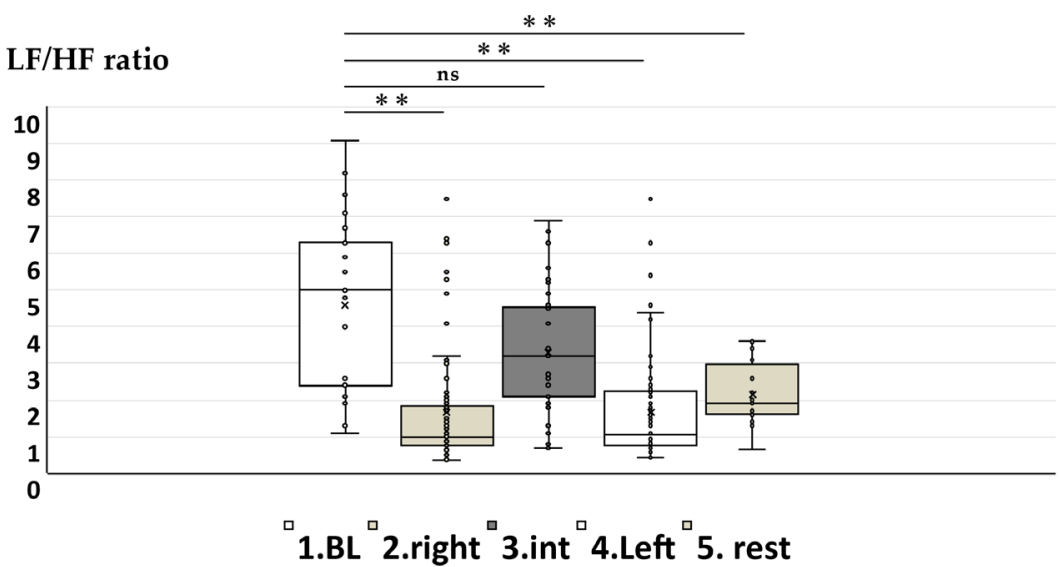

Figure 9. Comparison of ANS balance (LF/HF ratio) in HCT of Group E ( $n=7)$. The Mann-Whitney $U$ test was performed in in comparison with BL. ns: no significant, ${ }^{\star} \mathrm{p}<0.05,{ }^{* *} \mathrm{p}<0.01$. 


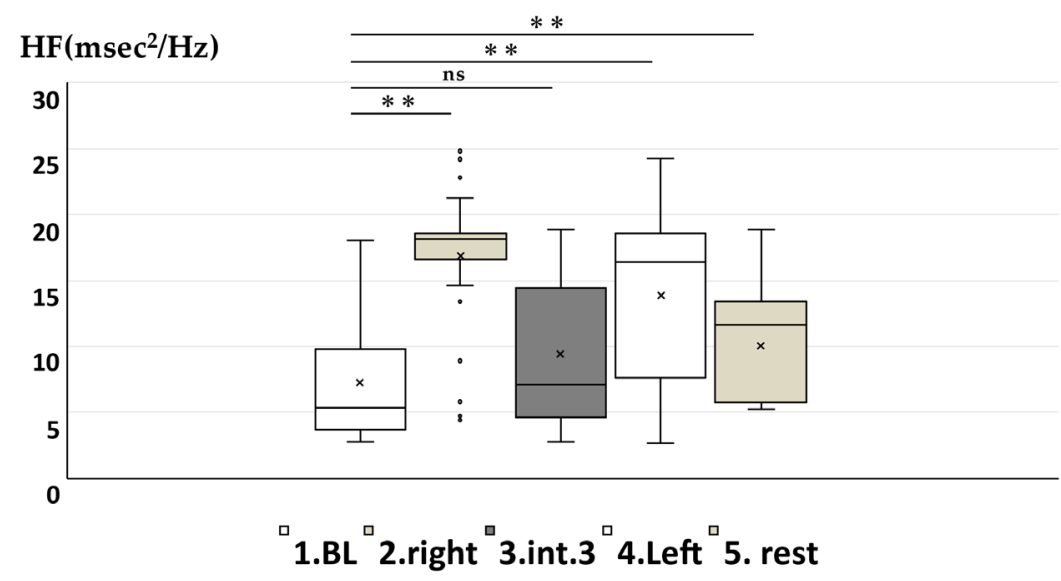

Figure 10. Comparison of ANS balance (HF) in HCT of Group F $(n=15)$. The Mann-Whitney $U$ test was performed in in comparison with BL. ns: no significant, ${ }^{*} \mathrm{p}<0.05,{ }^{* *} \mathrm{p}<0.01$.

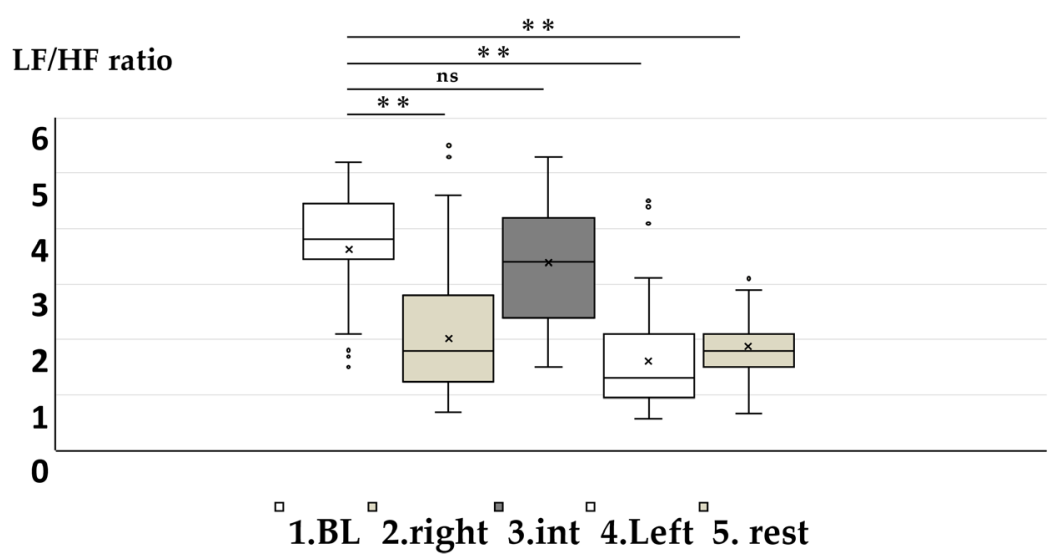

Figure 11. Comparison of ANS balance (LF/HF ratio) in HCT of Group E ( $\mathrm{n}=$ 7). The Mann-Whitney $U$ test was performed in in comparison with BL. ns: no significant, ${ }^{\star} \mathrm{p}<0.05,{ }^{* *} \mathrm{p}<0.01$.

Both Group E and Group F tended to improve cognitive function in IX, improve iADL, and decrease depressive tendency compared to VIII. Therefore, it is shown that weekly HCT activities could reduce the adverse effects of COVID 19 on the body and mind.

In 2020, a global pandemic of COVID-19 was reported, it was also reported that COVID-19 tends to be more severe in older people and has a higher mortality rate [31] [32] [33] [34] [35]. As a matter of course, there are many reports that COVID-19 severely ill people often have weakened immunity due to the elderly and chronic diseases. HCT and touch care are said to promote the secretion of oxytocin, a well-being hormone in the brain [36] [37]. It has also been reported that oxytocin is also effective in building relationships [38] [39].

On the other hand, there are reports that France and Germany recommend that horticultural activities were used as a communication tool and to eliminate the lack of exercise in the corona virus. The authors announced that horticultural therapy could easily trigger communication for people with dementia, and 
that it can activate long-term memory of the past and hope of living in the future. We also reported that the sympathetic nervous system (SNS) decreased, and the parasympathetic nervous system (PNS) increased during garden activities as active horticultural therapy. Furthermore, as a passive horticultural therapy, it was shown to improve the balance of autonomic nerves (ANS) when performing hand care treatment (HCT) using ingredients of horticultural crops such as a nut virgin oil and herbal extract.

In these studies, the autonomic balance of the elderly who had been away from horticultural therapy activities for a long time and those who participated continuously was measured at the time of IX evaluation. It became clear that both Group E and Group F show good changes in ANS balance. Therefore, by utilizing horticultural therapy that utilizes the power of nature and plants in addition to utilizing welfare facilities for the elderly, it was expected to lead to prevention cognitive impairment and behavior such as depressive views and depressive tendencies by COVID-19.

\section{Disclaimer}

Since this study was conducted only for the elderly who are using the outpatient welfare facility for the elderly among the participants of the continuing study, the $\mathrm{N}$ number is not sufficient. In addition, since this study is the result of one region of Japan, verification in regions with different medical, health, welfare environments and cultures were insufficient. Therefore, it is necessary to continue the research in the future.

\section{Conflicts of Interest}

The authors declare no conflicts of interest regarding the publication of this paper.

\section{References}

[1] Dixon, L.E., Mattons, R.H. and Jurich, A.P. (1987) Human Stress Reduction through Horticultural Vocational Training. HortScience, 22, 655-656.

[2] Ulrich, R.S., Simons, R.F., Losito, B.D., Fiorito, E., Miles, M.A. and Zelson, M. (1991) Stress Recovery during Exposure to Natural and Urban Environments. Journal of Environmental Psychology, 11, 201-230. https://doi.org/10.1016/S0272-4944(05)80184-7

[3] Yamada, M., Kimura, Y., Ishiyama, D., et al. (2020) Effect of the COVID-19 Epidemic on Physical Activity in Community-Dwelling Older Adults in Japan: A Cross-Sectional Online Survey. The Journal of Nutrition, Health and Aging. https://www.ncbi.nlm.nih.gov/pmc/articles/PMC7308797/

[4] Japan Society for Dementia Prevention (2020) Related to New Coronavirus Infection. Questionnaire Total Result. http://ninchishou.jp/publics/index/150/Downloads/202010081419406792\%20(1).pd $\underline{\mathrm{f}}$

[5] Armitage, R. and Nellums, L.B. (2020) COVID-19 and the Consequences of Isolating the Elderly. Lancet Public Health, 5, e256. 
https://doi.org/10.1016/S2468-2667(20)30061-X

[6] Yang, Y., Li, W., Zhang, Q., et al. (2020) Mental Health Services for Older Adults in China during the COVID-19 Outbreak. Lancet Psychiatry, 7, e19.

https://doi.org/10.1016/S2215-0366(20)30079-1

[7] Grant, W.B., Lahore, H., McDonnell, S.L., et al (2020) Evidence That Vitamin D Supplementation Could Reduce Risk of Influenzas and COVID-19 Infections and Deaths. Nutrients Actions, 12, E988.

https://doi.org/10.20944/preprints202003.0235.v2

[8] Ilie, P.C., Stefanescu, S. and Smith, L. (2020) The Role of Vitamin D in the Prevention of Coronavirus Disease 2019 Infection and Mortality. Aging Clinical and Experimental Research, 6, 1-4. https://doi.org/10.21203/rs.3.rs-21211/v1

[9] Alipio, M. (2020) Vitamin D Supplementation Could Possibly Improve Clinical Outcomes of Patients Infected with Coronavirus-2019 (COVID-19).

https://papers.ssrn.com/sol3/papers.cfm?abstract_id=3616008 https://doi.org/10.2139/ssrn.3571484

[10] Wise, J.A. and Rosenberg, E.J. (1988) The Effects of Interior Treatments on Performance Stress in Three Types of Mental Tasks. Ctr. Integrated Facilities Res. Technical Rpt. No. 002-02-1988, Grand Valley State Univ., Allendale.

[11] Shibata, M., Ohara, T., Hosoi, M., Jun, H., Yoshida, D., Hirabayashi, H., Morisaki, Y., Nakazawa, T., Mihara, A., Nagata, T., Oishi, E., Anno, K., Sudo, N. and Ninomiya, N. (2020) Emotional Loneliness Is Associated with a Risk of Dementia in a General Japanese Older Population: The Hisayama Study. The Journals of Gerontology, Series B: Psychological Sciences and Social Sciences, gbaa196.

https://doi.org/10.1093/geronb/gbaa196

[12] Koura, S. and Yamagishi, K. (2005) Stimulation Senses Evaluating Student Responses to Horticultural Therapeutic Activities and Blindfolded Harvest of Blueberry. ISHS Acta Horticulturae, 672, 185-189. https://doi.org/10.17660/ActaHortic.2005.672.21

[13] Kunikata, H. (2012) The Effects Measurement of Hand Massage by the Autonomic Activity and Psychological Indicators. The Journal of Medical Investigation, 59, 206-212. https://doi.org/10.2152/jmi.59.206

[14] Koura, S., Okawa, H., Oshikawa, T., Ueda, T., Nishikawa, C., Ikeda, A. and Kamijyo, K. (2018) Dementia Protective Efficacy by the Combination of Active and Passive Horticultural Therapy for All Person Concerned. International Symposium on Greener Cities for More Efficient Ecosystem Service in a Climate Changing World, Vol. 1, 223-231. https://doi.org/10.17660/ActaHortic.2018.1215.41

[15] Petersen, R.C., Smith, G.E., Waring, S.C., et al. (1999) Mild Cognitive Impairment: Clinical Characterization and Outcome. Archives of Neurology, 56, 303-308.

https://doi.org/10.1001/archneur.56.3.303

[16] Koura, S., Ikeda, A., Fujioka, Y., Mizogami, Y., Higashi, K. and Oshikawa, T. (2020) Effects of Hand Care Therapy on Reducing the Conversion Rate from MCI to Dementia and Role of COVID-19 as Non-Pharmacotherapy. Open Journal of Therapy and Rehabilitation, 8, 42-52.

https://www.scirp.org/journal/paperinformation.aspx?paperid=100803

[17] Pagani, M.F., Lombardi, S., Guzzetti, O., Rimoldi, R., Furlan, P., Pizzinelli, G., Sandrone, G., Malfatto, S., Dell'Orto and Piccaluga, E. (1986) Power Spectral Analysis of Heart Rate and Arterial Pressure Variabilities as a Marker of Sympathovagal Interaction in Man and Conscious Dog. Circulation Research 59, 178-193. https://doi.org/10.1161/01.RES.59.2.178

[18] Akselrod, S.D., Gordon, F.A., Ubel, D.C., et al. (1981) Power Spectrum Analysis of 
Heart Rate Fluctuation; a Quantitative Probe of Heart-to-Beat Cardiovascular Control. Science, 213, 220-222. https://doi.org/10.1126/science.6166045

[19] Kanaya, N., Hirata, N., Kurosawa, S., Nakayama, M. and Namiki, A. (2003) Differential Effects of Propofol and Sevoflurane on Heart Rate Variability. Anesthesiology, 98, 34-40. https://doi.org/10.1097/00000542-200301000-00009

[20] Musa, S., Jean-Rodolphe, V., Dominique, L., Philippe, C., Gery, B., Jean, G., Michel, B. and Pierre, M. (2002) L'hyperreflexie autonome induite par la stimulation des racines sacrees est detedtee par l'analyse spectrale de l'ECG. Canadian Journal of Anesthesia, 49, 936-941. https://doi.org/10.1007/BF03016878

[21] Espino, D.V., Lichtenstein, M.J., Palmer, R.F. and Hazuda, H.P. (2004) Evaluation of the Mini-Mental Status Examination's Internal Consistency in a Community-Based Sample of Mexican-American and European-American Elders: Results from the San Antonio Longitudinal Study of Aging. Journal of the American Geriatrics Society, 52, 822-827. https://doi.org/10.1111/j.1532-5415.2004.52226.x

[22] Folstein, M.F., Folstein, S.E. and McHugh, P.R. (1975) Mini-Mental State: A Practical Method for Grading the Cognitive State of Patients for the Clinician. Journal of Psychiatric Research, 12, 189-198. https://doi.org/10.1016/0022-3956(75)90026-6

[23] Ganguli, M., Ratcliff, G. and Huff, F.J. (1990) Serial Sevens versus World Backwards: A Comparison of the Two Measures of Attention from the MMSE. Journal of Geriatric Psychiatry and Neurology, 3, 203-207.

https://doi.org/10.1177/089198879000300405

[24] Guerrero, B.E., Luo, X. and Schmeidler, J. (2009) The MMSE Orientation for Time Domain Is a Strong Predictor of Subsequent Cognitive Decline in the Elderly. International Journal of Geriatric Psychiatry, 24, 1429-1437. https://doi.org/10.1002/gps.2282

[25] Morales, L.S., Flowers, C., Gutierrez, P., Kleinman, M. and Teresi, J.A. (2006) Item and Scale Differential Functioning of the Mini-Mental Status Exam Assessed Using the Differential Item and Test Functioning (DFIT) Framework. Medical Care, 44, S143-S151. https://doi.org/10.1097/01.mlr.0000245141.70946.29

[26] Nasreddine, Z.S., Phillips, N.A., Bédirian, V., Charbonneau, S., Whitehead, V., Collin, I., Cummings, J.L. and Chertkow, H. (2005) The Montreal Cognitive Assessment, Moca-J: A Brief Screening Tool for Mild Cognitive Impairment. Journal of the American Geriatrics Society, 53, 695-699. https://doi.org/10.1111/j.1532-5415.2005.53221.x

[27] Koyano, W., Shibata, H., Nakazato, K., Haga, H. and Suyama, Y. (1991) Measurement of Competence: Reliability and Validity of the TMIG Index of Competence. Archives of Gerontology and Geriatrics, 13, 103-116. https://doi.org/10.1016/0167-4943(91)90053-S

[28] Kumagai, S., Shibata, H., Watanabe, S., Suzuki, T., Haga, H., Osada, H. and Teraoka, K. (1999) An Intervention Trial to Postpone Aging in Competent Elderly. Trial of Nutritional Improvement in the Retirement Home. Nihon Koshu Eisei Zasshi, 46, 1003-1012.

[29] Tanaka, C., Yoshida, H., Amano, H., Kumagai, S., Fujiwara, Y., Tsuchiya, Y. and Shinkai, S. (2006) Physical Activity Level and Physical, Mental and Social Factor in Community-Dwelling Elderly People. Japanese Journal of Public Health, 53, 671-680.

[30] Yang, Y. and Kwak, Y.T. (2016) The Effects of Donepezil on 15-Item Geriatric Depression Scale Structure in Patients with Alzheimer Disease. Dementia and Geriatric Cognitive Disorders Extra, 6, 437-446. https://doi.org/10.1159/000449244

[31] Verity, R., Okell, L.C., Dorigatti, I., Winskill, P., Whittaker, C., et al. (2020) Esti- 
mates of the Severity of Coronavirus Disease 2019: A Model-Based Analysis. The Lancet Infectious Disease, 20, 669-677. https://doi.org/10.1016/S1473-3099(20)30243-7

[32] WHO (2020) Report of the WHO-China Joint Mission on Coronavirus Disease 2019 (COVID-19).

https://www.who.int/publications-detail/report-of-the-who-china-joint-mission-on -coronavirus-disease-2019-(covid-19)

[33] WHO (2020) Coronavirus Disease 2019 (COVID-19) Situation Report 43. https://www.who.int/docs/default-source/coronaviruse/situation-reports/20200303sitrep-43-covid-19.pdf?sfvrsn=2c21c09c_2

[34] Jung, S., Akhmetzhanov, A.R., Hayashi, K., et al. (2020) Real-Time Estimation of the Risk of Death from Novel Coronavirus (COVID-19) Infection: Inference Using Exported Cases. Journal of Clinical Medicine, 9, E523.

https://doi.org/10.3390/jcm9020523

[35] Famulare, M. (2020) 2019-nCoV: Preliminary Estimates of the ConfirmedCase-Fatality-Ratio and Infection-Fatality-Ratio, and Initial Pandemic Risk Assessment.

[36] Moberg, U.K. (2000) The Oxytocin Factor: Tapping the Hormone of Calm, Love, and Healing. Journal of Midwifery \& Women's Health, 50, e6. https://doi.org/10.1016/j.jmwh.2004.07.002

[37] Moberg, U.K., Handlin, L. and Petersson, M. (2014) Self-Soothing Behaviors with Particular Reference to Oxytocin Release Induced by Non-Noxious Sensory Stimulation. Frontiers in Psychology, 5, 1529. https://doi.org/10.3389/fpsyg.2014.01529

[38] Matthiesen, A.S., Ransjö, A.B., Nissen, E. and Uvnäs, M.K. (2001) Postpartum Maternal Oxytocin Release by Newborns: Effects of Infant Hand Massage and Sucking. Birth, 28, 13-19. https://doi.org/10.1046/j.1523-536x.2001.00013.x

[39] Light, K.C., Grewen, K.M. and Amico, J.A. (2005) More Frequent Partner Hugs and Higher Oxytocin Levels Are Linked to Lower Blood Pressure and Heart Rate in Premenopausal Women. Biological Psychology, 69, 5-21.

https://doi.org/10.1016/j.biopsycho.2004.11.002 